\title{
DATING OF THE TASHTYK CULTURAL REMAINS FROM THE OGLAKHTY BURIAL GROUND (SOUTHERN SIBERIA)
}

\author{
G I Zaitseva $a^{1,2} \bullet$ S V Pankova ${ }^{3} \cdot$ S S Vasiliev ${ }^{4} \cdot V_{\text {A Dergachev }}^{4} \bullet$ E M Scott $^{5} \bullet$ A A Sementsov $^{1} \bullet$ \\ H Jungner ${ }^{6}$ E Sonninen ${ }^{6}$
}

\begin{abstract}
The present research is focused on the dating of the Oglakhty burial ground, the key site of stage I of the Tashtyk culture. Despite the numerous well-preserved burials of that type investigated at the Oglakhty complexes, their chronological position has remained unclear. From the early 20th century until the present, 2 different time periods had been identified for the Tashtyk burials: (1) from the 1st century BC until the 1st century AD and (2) from the 1st until the 2nd century AD. New data obtained in the 1990s suggested a different age for Tashtyk burials, namely the 3rd-4th centuries AD. This considerable shift in chronology needed to be checked with independent data. The chronological position of one of the Oglakhty burials, tomb 4, has been investigated with the use of wiggle-matching, applied to wooden logs used in the construction of tomb 4 . The resulting dates for this burial strongly suggest its age as being limited to the 3rd-4th centuries AD, which is corroborated by the archaeological dates of the imported artifacts found in the grave and which is in agreement with the chronological position of the Oglakhty site, as proposed by previous investigations.
\end{abstract}

\section{INTRODUCTION}

The Oglakhty burial ground is located in the Republic of Khakasia in southern Siberia on the left bank of the Yenisei River (Figure 1). The site is attributed to the first stage of the Tashtyk culture, featuring the appearance of flat graves. More than 200 burials of this type are known, most of them being poor in finds and containing no material suitable for dating. The Oglakhty burial ground is unique due to its well-preserved organic matter. Human mummies, articles of clothing, wooden implements, and textiles were found in several graves at the site.

The Oglakhty burial ground was discovered in 1903 by A V Adrianov, with 3 out of 17 investigated graves being well preserved (Adrianov 1903). The excavations were resumed in the late 1960s. In 1969-1973, 7 graves were studied by E B Vadetskaya and L R Kyzlasov. The Oglakhty site contains about 250 Tashtyk-type burials (Vadetskaya 1999:230), the greater part of them remaining unstudied. A national reserve has been established in the Oglakhty Mountains recently, prohibiting all further excavations in that area.

Tomb 4 excavated by Kyzlasov contained an intact archaeological complex with well-preserved organic materials (Kyzlasov 1971a,b). The burial pit $(2.5 \times 1.5 \mathrm{~m})$ was hermetically sealed with bark birch on all sides. The burial chamber contained the mummies of a male and a female, their faces covered with painted plaster masks. The burial inventory included clothes, with fur caps and jackets, trousers, mittens, and shoes among them. The entire body of the male mummy was tattooed (Kyzlasov and Pankova 2004). Besides the mummies, "dolls" representing leather copies of human bodies were found. There were also wooden blocks and leather pillows under the heads of the mummies and the dolls, as well as a number of clay and wooden vessels, a model of a bow with arrows, details of miniature bridles, and other goods. All the objects from Oglakhty tomb 4, including a wooden chamber, are presently exhibited at the State Hermitage Museum, where their full restoration had

\footnotetext{
${ }^{1}$ Institute for the History of Material Culture, St. Petersburg, Russia.

${ }^{2}$ Corresponding author. Email: ganna@ mail.wplus.net.

${ }^{3}$ The State Hermitage Museum, St. Petersburg, Russia.

${ }^{4}$ The A.F. Ioffe Physical Technical Institute, St. Petersburg, Russia.

${ }^{5}$ Glasgow University, Department of Statistics, Glasgow, Scotland.

${ }^{6}$ University of Helsinki, Helsinki, Finland.
}

(C) 2009 by the Arizona Board of Regents on behalf of the University of Arizona

Proceedings of the 5th International ${ }^{14} \mathrm{C}$ and Archaeology Symposium, edited by Irka Hajdas et al.

RADIOCARBON, Vol 51, Nr 2, 2009, p 423-431 


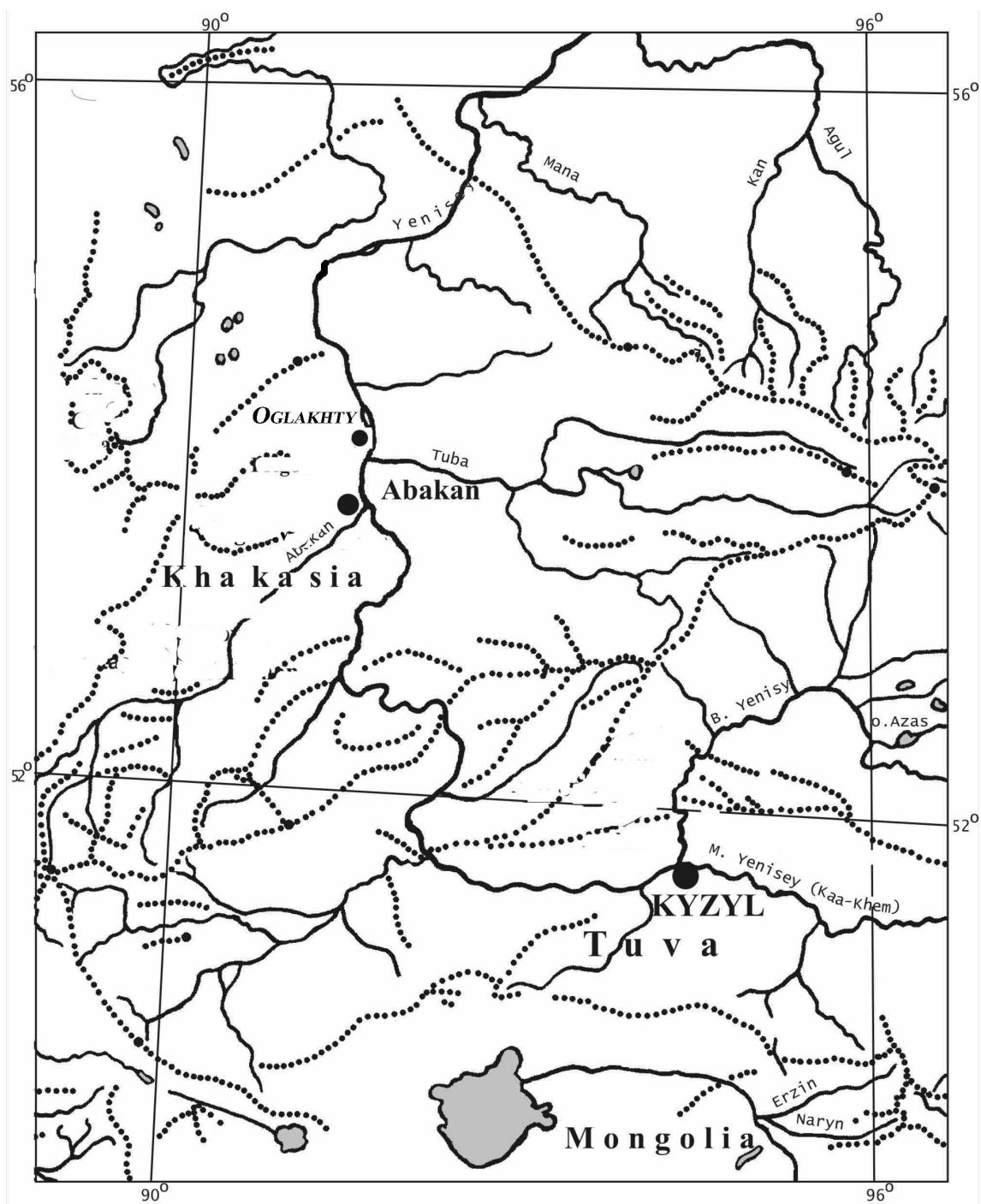

Figure 1 Map of the location of the Oglakhty burial ground

been carried out. These materials have been discussed in several publications (Kyzlasov 1971a,b; Zavituhina and Barkova 1978; Alekseev et al. 2001; Kyzlasov and Pankova 2004; Pankova 2005).

It should be noted that until recently, the age of the Oglakhty tomb 4 had never been specifically discussed. Kyzlasov originally had dated the site to the 1st century BC (Kyzlasov 1971a,b), but in later publications the age had been shifted to the beginning of the Christian era (Kyzlasov and Pankova 2004). The age of stage I of the Tashtyk culture as a whole remains under scientific discussion.

In general terms, there are 2 concepts regarding the age of the Tashtyk flat graves: 1) they date to the 1st and the 2nd centuries AD (Teploukhov 1929; Kiselev 1949; Bernshtam 1951; Gryaznov 1971); or 2) they date to the 1st century BC and the 1st century AD (Sosnovski 1933; Tallgren 1937; Kyzlasov 1960, 1971a). 
Until the last decade, there was little or no pertinent information for the precise dating of these complexes as they included no archaeologically datable materials. Initially, the date of Tashtyk burials was based on analogs with the grave goods and funeral rites, obtained from the elite barrows of Noin-Ula, Katanda, and Shibe, dating to the Christian era. Similarly to the Oglakhty graves, the organic materials of these complexes were well preserved, making it possible to compare them with the Oglakhty ones and consequently suggest their contemporaneity. Other datable materials included glass beads, resembling the Sarmatian ones, and items similar to the artifacts originated from the Hunnic burials of Central Asia. But in fact, there were no methods for analyzing glass beads. As for the analogs from Noin-Ula, they could provide only a wide chronological range.

A new motive for the chronological investigations of the Tashtyk flat graves resulted from the studies of silk fabrics. In 1973, K Ribu and E I Lubo-Lesnichenko found that the polychrome textiles from the Oglakhty site had direct analogs with the silks from the Loulan trade center in eastern Turkestan (Ribu and Lubo-Lesnichenko 1973). Lubo-Lesnichenko (1994) suggested that the finds from Loulan should be dated to the 3rd to beginning of the 4th century $\mathrm{AD}$, and the textiles from the Oglakhty site should date accordingly. Unfortunately, the proposed new date suggested for Oglakhty burials passed almost unnoticed.

Later, in 1999, Vadetskaya published results of new investigations of archaeological materials from the Tashtyk sites. According to her detailed study of the structure of the burials and the burial rites, the Oglakhty tombs were chronologically dissimilar and stretched over a wide chronological interval (Vadetskaya 1999). In addition, the chemical analysis of the glass beads from the flat graves carried out by V G Galibin showed that according to the production technique, some of the beads cannot be earlier than the 2nd century AD (Vadetskaya 1999). As a result, Vadetskaya suggested the widening of the chronological interval of the Tashtyk culture (stage I) and suggested its age as spanning from the 1 st to the 4 th centuries $\mathrm{AD}$.

In spite of this new evidence, the problem of the chronology for the Tashtyk flat tombs still needs further consideration. The archaeological typology provides only the relative position of the Oglakhty complex, and the age of the original Turkestan silks should be checked. Such a considerable change in the chronology needs to be confirmed with independent data. This paper presents results of a ${ }^{14} \mathrm{C}$ dating program aimed at establishing a more precise chronology for the Oglakhty complex.

In $2005,{ }^{14} \mathrm{C}$ dating of $2 \operatorname{logs}$ from the chamber wall was begun with the intention of using wigglematching. In spring 2007, the first preliminary results were published (Zaitseva et al. 2007). This paper presents the full set of ${ }^{14} \mathrm{C}$ results and their interpretation.

\section{MATCHING OF THE RADIOCARBON DATA TO THE CALIBRATION CURVE}

The wooden chamber of the Oglakhty tomb 4 was well preserved, which enabled wiggle-matching to be carried out. This approach has been used in Siberian archaeology to date the pre-Scythian and Scythian barrows (Kuzmin et al. 2004; Zaitseva et al. 2005; Panyushkina et al. 2007). The Oglakhty grave is the first site of the latter period where wiggle-matching has been used.

The majority of the logs from the chamber of the Oglakhty tomb 4 have been well preserved. In 1970-80, this timberwork was exhibited at a permanent exhibition in the State Hermitage Museum (Figure 2), but the chamber is presently deconstructed. The size of the chamber was 2.3 by $1.55 \mathrm{~m}$, and $0.85 \mathrm{~m}$ high. The log house consisted of 2- to 3-log-high walls and a ceiling of $9 \operatorname{logs}$, indicated with marks (Kyzlasov and Pankova 2004). The chamber was hermetically sealed with bark birch with the pressed soil above the chamber ceiling intact. Microscopic analysis of the timber logs sug- 
gested that 7 logs of pine (Pinus sylvestris Z.) and 12 logs of larch (Larix sp.) were used for the chamber (Zaitseva et al. 2007). Two samples suitable for the selection of individual tree rings have been chosen for ${ }^{14} \mathrm{C}$ analysis: a pine log from the ceiling (with 7 marks) and a larch $\log$ from the upper part of the chamber wall. The pine log contained 186 annual rings and the larch one, 210 rings. The outermost tree rings were not measured because they were badly degraded. For ${ }^{14} \mathrm{C}$ dating, the wooden samples were subdivided into blocks of 10 annual rings.

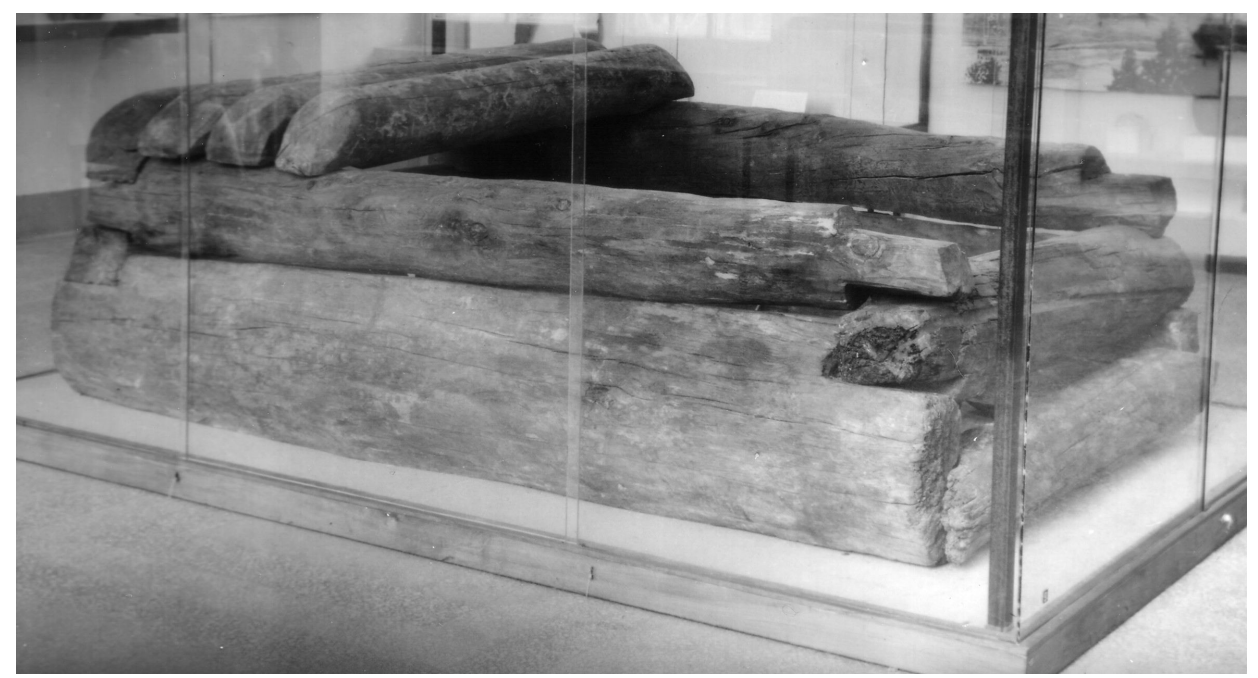

Figure 2 The chamber of the Oglakhty grave 4 (from the former State Hermitage exhibition)

${ }^{14} \mathrm{C}$ dating has been carried out at the ${ }^{14} \mathrm{C}$ Laboratory of the Institute for the History of Material Culture, the ${ }^{13} \mathrm{C} /{ }^{12} \mathrm{C}$ ratio was measured at the University of Helsinki, and the wiggle-matching was conducted in the Physical-Technical Institute, St. Petersburg. In early 2007, the dates of the larch sample were published, suggesting an interval of cal AD 267-289 for the chamber construction (Zaitseva et al. 2007). As the pine samples have now been dated, it is possible to compare and to correlate the dates from the 2 wood species. The ${ }^{14} \mathrm{C}$ dates obtained for the larch and pine tree rings are presented in Tables 1 and 2.

To determine the chronological position of the barrow, wiggle-matching (Blaauw et al. 2003) was carried out. For this case, the method can be simplified as the time distance between the samples in the 2 series is known from tree-ring counting.

The approach consists of the following: We consider the ${ }^{14} \mathrm{C}$ age $R_{i}$ of the sample $i$ as the sum: $R_{i}=$ $Y_{i}+\Delta Y$, where $Y_{i}$ is the measured ${ }^{14} \mathrm{C}$ age of the sample and $\Delta Y$ the adjustment due to laboratory bias. The quantity $\Delta Y$ should be calculated. For finding a calendar age, the function considered is

$$
\Phi \Delta(Y, \tau)=\sum_{k=1}^{N} \frac{\left|y_{k}+\Delta y-C\left(\tau+\Delta \tau_{k}\right)\right|^{2}}{\sigma_{k}^{2}}
$$

where $C(\tau)$ is the calibration function, $\Delta \tau_{\mathrm{k}}$ the age of ring $k$ relative to the age of the sample $\tau$, and $\sigma_{k}$ the error of measurement for $k$ th ring. 
Table $1{ }^{14} \mathrm{C}$ dates of the pine tree rings. The corrected age is corrected for isotopic fractionation based on the measured $\delta^{13} \mathrm{C}$ values.

\begin{tabular}{lclll}
\hline Laboratory nr & Tree-ring $\mathrm{nr}$ & $\begin{array}{l}\text { Measured }{ }^{14} \mathrm{C} \text { age } \\
\left(A_{0}\right)\end{array}$ & $\begin{array}{l}\delta^{13} \mathrm{C} \\
(\%)\end{array}$ & $\begin{array}{l}\text { Corrected }{ }^{14} \mathrm{C} \text { age } \\
\left(A_{\text {cor }}\right)\end{array}$ \\
\hline Le-7338 & $1-10$ & $1884 \pm 70$ & -24.99 & $1884 \pm 70$ \\
Le-7337 & $11-20$ & $1934 \pm 30$ & -26.65 & $1907 \pm 30$ \\
Le-7332 & $21-30$ & $1885 \pm 40$ & -24.03 & $1901 \pm 40$ \\
Le-7340 & $31-40$ & $1885 \pm 25$ & -24.06 & $1900 \pm 25$ \\
Le-7336 & $41-50$ & $1918 \pm 30$ & -23.99 & $1934 \pm 30$ \\
Le-7339 & $51-60$ & $1752 \pm 20$ & -23.86 & $1770 \pm 20$ \\
Le-7341 & $61-70$ & $1775 \pm 80$ & -24.26 & $1787 \pm 80$ \\
Le-7326 & $71-80$ & $1773 \pm 25$ & -24.51 & $1781 \pm 25$ \\
Le-7334 & $81-90$ & $1775 \pm 35$ & -25.25 & $1771 \pm 35$ \\
Le-7335 & $91-100$ & $1836 \pm 35$ & -24.62 & $1842 \pm 35$ \\
Le-7342 & $101-110$ & $1835 \pm 30$ & -23.99 & $1851 \pm 30$ \\
Le-7333 & $111-120$ & $1810 \pm 35$ & -24.07 & $1825 \pm 35$ \\
Le-7329 & $121-130$ & $1752 \pm 25$ & -23.26 & $1780 \pm 25$ \\
Le-7327 & $131-140$ & $1763 \pm 25$ & -23.06 & $1794 \pm 25$ \\
Le-7330 & $141-150$ & $1737 \pm 35$ & & $1766 \pm 35$ \\
Le-7328 & $151-160$ & $1845 \pm 80$ & -23.19 & $1874 \pm 80$ \\
Le-7331 & $161-166$ & $1670 \pm 80$ & & $1699 \pm 80$ \\
\hline
\end{tabular}

Table $2{ }^{14} \mathrm{C}$ dates of the larch tree rings. The corrected age is corrected for isotopic fractionation based on the measured $\delta^{13} \mathrm{C}$ values.

\begin{tabular}{lclll}
\hline Laboratory $\mathrm{nr}$ & Tree-ring $\mathrm{nr}$ & $\begin{array}{l}\text { Measured }{ }^{14} \mathrm{C} \text { age } \\
\left(A_{0}\right)\end{array}$ & $\begin{array}{l}\delta^{13} \mathrm{C} \\
(\%)\end{array}$ & $\begin{array}{l}\text { Corrected }{ }^{14} \mathrm{C} \text { age } \\
\left(A_{\text {cor }}\right)\end{array}$ \\
\hline Le-7349 & $41-50$ & $1875 \pm 50$ & -20.14 & $1953 \pm 50$ \\
Le-7344 & $51-60$ & $1878 \pm 35$ & -19.90 & $1960 \pm 35$ \\
Le-7346 & $71-80$ & $1810 \pm 30$ & -20.41 & $1884 \pm 30$ \\
Le-7353 & $81-90$ & $1813 \pm 40$ & -20.49 & $1885 \pm 40$ \\
Le-7352 & $91-100$ & $1806 \pm 30$ & -20.58 & $1877 \pm 30$ \\
Le-7359 & $101-110$ & $1761 \pm 25$ & -20.04 & $1841 \pm 25$ \\
Le-7357 & $111-120$ & $1797 \pm 20$ & -19.95 & $1878 \pm 20$ \\
Le-7355 & $121-130$ & $1755 \pm 30$ & -20.16 & $1833 \pm 30$ \\
Le-7361 & $131-140$ & $1818 \pm 25$ & -20.87 & $1884 \pm 25$ \\
Le-7358 & $141-150$ & $1804 \pm 20$ & -20.33 & $1879 \pm 20$ \\
Le--7360 & $151-160$ & $1775 \pm 20$ & -20.05 & $1855 \pm 20$ \\
Le-7350 & $161-170$ & $1741 \pm 20$ & -19.78 & $1825 \pm 20$ \\
Le-7348 & $171-180$ & $1736 \pm 20$ & -20.07 & $1815 \pm 20$ \\
Le7354 & $181-190$ & $1708 \pm 25$ & -19.21 & $1801 \pm 25$ \\
\hline
\end{tabular}

In order to find the age of the sample, it is necessary to minimize $\phi(\Delta Y, \tau)$ on parameters $\Delta Y$ and $\tau$. The result of minimization gives the age of sample $\tau=\tau_{s}$ and the adjustment to the ${ }^{14} \mathrm{C}$ age $\Delta Y=\Delta Y_{s}$. The minimization process can have multiple solutions.

Using the larch and pine results, 2 possible solutions were found. The results are summarized in Table 3 , shown as the date for the outermost ring of the 2 trunks. The given error is specified as 2 standard deviations $(2 \sigma)$.

From the wiggle-matching of the ${ }^{14} \mathrm{C}$ measurements for the larch and pine, the time intervals corresponding to timberwork preparation were found. The dates from both species, for the early and late 
Table 3 Results from calibration (derived from Figures 3 and 4).

\begin{tabular}{llllll}
\hline & \multicolumn{2}{c}{ Early interval $\left(\tau_{s}\right)$} & & \multicolumn{2}{c}{ Late interval $\left(\tau_{s}\right)$} \\
\cline { 2 - 3 } \cline { 5 - 6 } Sample & Date $(\mathrm{AD})$ & Statistics $^{\mathrm{a}}$ & & Date $(\mathrm{AD})$ & Statistics \\
\hline Larch & $280 \pm 16$ & $p=0.1$ & & $387 \pm 17$ & $p=0.01$ \\
Pine & $275 \pm 21$ & $p=0.28$ & & $387 \pm 14$ & $p=0.002$ \\
Mean & $278 \pm 18$ & & & $387 \pm 15$ & \\
\hline \\
an the "Statistics" columns, the probability of agreement by chance between the ${ }^{14} \mathrm{C}$ \\
data and the calibration function is given.
\end{tabular}

intervals, do not differ significantly (the difference of dates is much less than the statistical error), and so are combined (by averaging) over the 2 species ("Mean" in Table 3). The results of the calibration do not unambiguously determine the burial date. This situation is due to the existence of a systematic laboratory error and properties of the calibration function. Two possible intervals for timberwork preparation result: early, AD 260-296, and late, AD 372-402 (95\%), as shown in Figures 3 and 4 . The early interval corresponds to a $\Delta Y$ value (adjustment) of +1 and $+58 \mathrm{yr}$ for the larch and pine, respectively, and for the late interval, the values are correspondingly, -106 and $-54 \mathrm{yr}$.

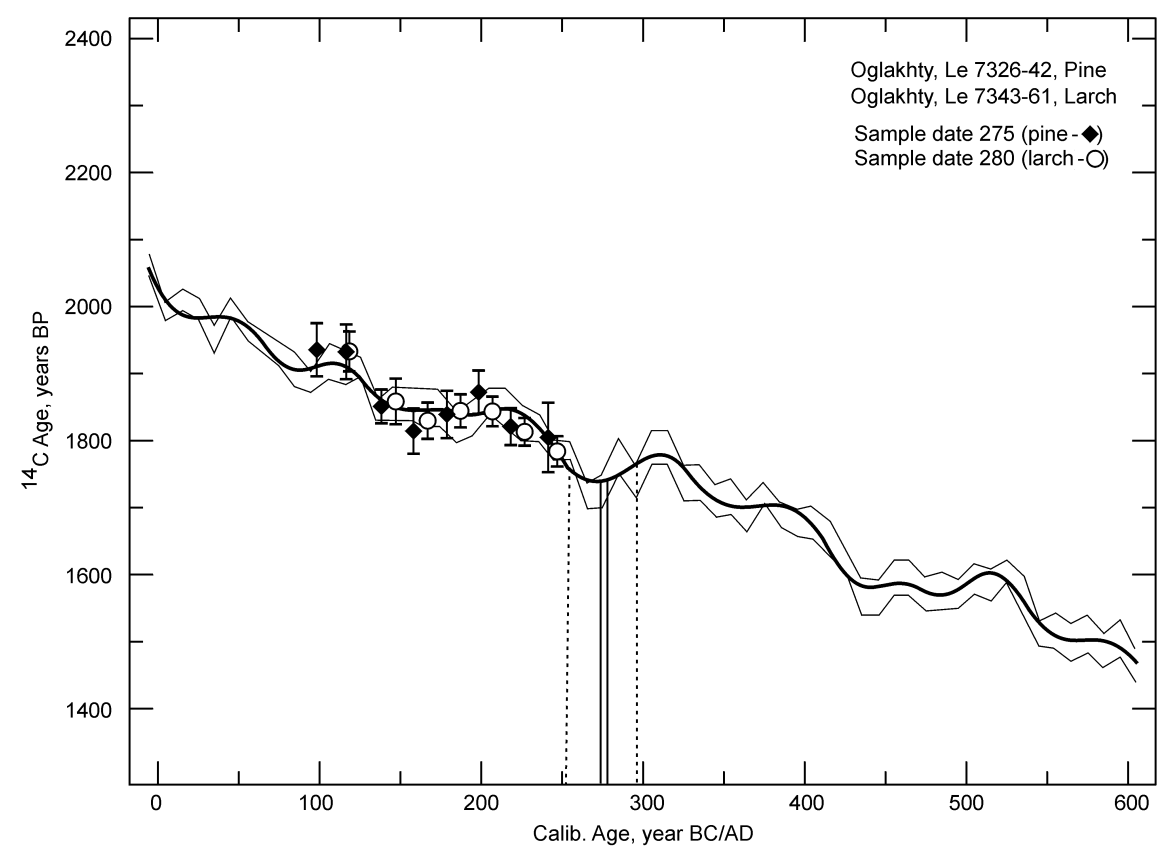

Figure 3 The wiggle-matching position of the ${ }^{14} \mathrm{C}$ dates for pine and larch with the calibration curve (earlier age).

In order to choose between the 2 periods, we calculated

$$
\chi^{2}=\sum_{i=1}^{N} \frac{\left(R_{i}-C_{i}\right)^{2}}{\sigma_{i}^{2}}
$$




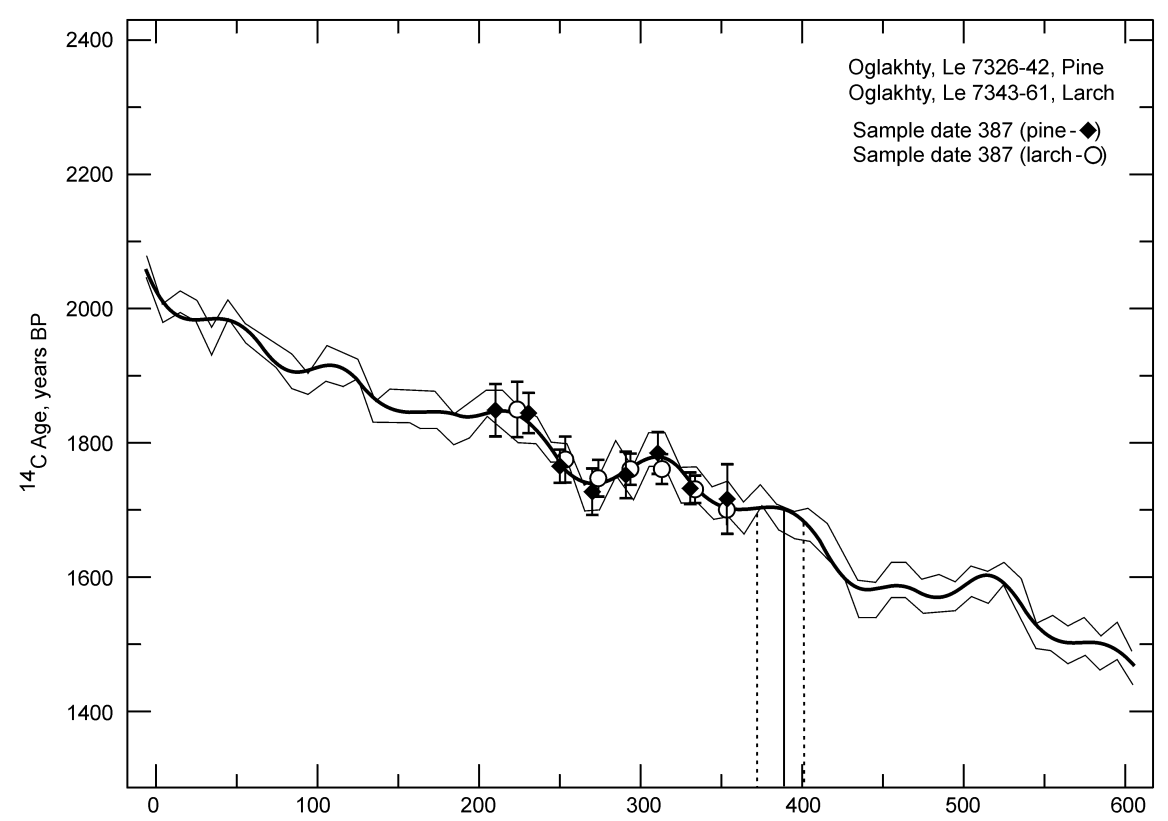

Figure 4 The wiggle-matching position of the ${ }^{14} \mathrm{C}$ dates for pine and larch with the calibration curve (later age)

which is a measure of agreement between the dates $R_{i}$ and the calibration curve $C_{i}$ and the variance $S^{2}$, connected by a simple relation:

$$
S^{2}=\frac{\chi^{2}}{N-1}
$$

where $N$ is the number of measurements. The parameter $S^{2}$ is a measure of the scatter of the ${ }^{14} \mathrm{C}$ dates relative to the calibration curve. The calculated values are summarized in Table 4.

Table 4 Variance of ${ }^{14} \mathrm{C}$ dates relative to the calibration curve.

\begin{tabular}{llllll}
\hline & \multicolumn{2}{c}{ Early interval } & & \multicolumn{2}{c}{ Late interval } \\
\cline { 2 - 3 } \cline { 5 - 6 } & Larch & Pine & & Larch & Pine \\
\hline$N$ & 7 & 8 & & 7 & 8 \\
$\chi^{2}$ & 2.23 & 4.51 & & 0.98 & 0.75 \\
$\mathrm{~S}^{2}$ & 0.37 & 0.64 & & 0.16 & 0.11 \\
$\mathrm{~S}^{2}$ & & 0.48 & & & 0.12 \\
\hline
\end{tabular}

The values in Table 4 indicate that the later interval for the 2 logs gives a better fit of the ${ }^{14} \mathrm{C}$ dates to the calibration curve (lower $\chi^{2}$ values), and consequently, the later interval is more probably the correct one. This, however, means that the laboratory bias $(\Delta Y)$ is different for the pine and the larch data sets and also that the bias is greater than the errors given for the single dates.

\section{CONCLUSIONS}

${ }^{14} \mathrm{C}$ dating of the timberwork from the Oglakhty tomb 4 using wiggle-matching has shown that its construction can be dated to 2 time intervals, AD 260-296 or 372-402. Subsequent statistical anal- 
ysis has enabled us to suggest that the later interval is more likely since there is better agreement between the ${ }^{14} \mathrm{C}$ dates and the calibration curve. This result provides confirmatory evidence that the complex of Oglakhty tombs 4 was formed no earlier than the end of the 3rd-4th centuries AD, which is in agreement with the age of the imported silk artifacts and supports Vadetskaya's conclusions about the age of the Tashtyk tombs as being from the 3rd and 4th centuries AD. However, it is important to continue research on these complex burial sites, to provide further checks on the age of Oglakhty tomb 4 using high-resolution ${ }^{14} \mathrm{C}$ chronologies.

\section{ACKNOWLEDGMENTS}

This research is supported by INTAS project No. 03-51-4445 and the Program of the Presidium RAS "Adaptation Character of the environmental changes and its influence on the development of the nomadic cultures of the Bronze Age-Iron Age in the steppe zone of Eurasia (2nd millennium BC-1st millennium AD)."

\section{REFERENCES}

Adrianov AV. 1903. The Oglakhty burial ground. Illustration supplement to the newspaper Siberian Life 249, 16 November 1903. In Russian.

Alekseev A, Arbore-Popescu G, Piotrovskij J, editors. 2001. Siberia: Gli Uomini dei Fiumi Ghiacciati. Milan: Electa. 209 p.

Bernshtam AN. 1951. Essay of the Huns' History. Leningrad. 256 p. In Russian.

Blaauw M, Heuvelink GBM, Mauquoy D, van der Plicht J, van Geel B. 2003. A numerical approach to C-14 wiggle-match dating of organic deposits: best fits and confidence intervals. Quaternary Science Reviews 22(14):1485-500.

Gryaznov MP. 1971. Miniatures of the Tashtyk culture. Archaeological Articles of the State Hermitage Museum 13:94-106. In Russian.

Kiselev SV. 1949. The Ancient History of Southern Siberia. Moscow: Moscow State University Press. 364 p. In Russian.

Kuzmin YV, Slusarenko IY, Hajdas I, Bonani G, Christen JA. 2004. The composition of ${ }^{14} \mathrm{C}$ wiggle-matching results for the "floating" tree-ring chronology of the Ulandryk-4 burial ground (Altai Mountains, Siberia). Radiocarbon 46(2):943-8.

Kyzlasov LR. 1960. The Tashtyk epoch in the history of the Khakassian-Minusinsk depression (II century BCV century AD). Moscow: Moscow State University Press. 197 p. In Russian.

Kyzlasov LR. 1971a. Khakassian archaeological expedition of 1969. Proceedings of the Khakassian Institute for the Language, Literature and History. Historical Series. Abakan. XVI (3):173-6. In Russian.

Kyzlasov L. 1971b. Das Grabmal am Jenissei. Ideen des exakten Wissen. Herausgegeben in Verbindung mit der Academie der Wissenschaften der UdSSR. 8:51722. Stuttgart.

Kyzlasov LR, Pankova SV. 2004. Tattoo on an ancient mummy from Khakasia. Turn of the Christian era. Reports of the State Hermitage Museum LXII:61-7. In
Russian.

Lubo-Lesnichenko EI. 1994. China on the Silk Road. Moscow. 326 p. In Russian.

Pankova SV. 2005. New images of Tashtyk art and their parallels. In: Archaeology of Southern Siberia: Ideas, Methods, Discoveries. (Reports of the international conference dedicated to 100th anniversary of SV Kiselev). Krasnoyarsk. p 183-5.

Panyushkina I, Sljusarenko I, Bikov N, Bogdanov E. 2007. Floating larch tree-ring chronologies from archaeological timbers in the Russian Altai between about 800 BC and AD 800. Radiocarbon 49(2):693702.

Ribu K, Lubo-Lesnichenko EI. 1973. The Oglakhty and Loulan (two groups of ancient artificial textiles). Countries and Peoples of the East XV:272-81. In Russian.

Sosnovski GP. 1933. About the finds of the Oglakhty burial ground. The Problems of the History of Material Culture 7-8:34-41. In Russian.

Tallgren AM. 1937. The south Siberian cemetery of Oglakty from the Han period. Eurasia Septentrionalis Antiqua XI:69-90. Helsinki.

Teploukhov SA. 1929. The classification experience of the ancient metal cultures of the Minusinsk district. Materials on the Ethnology 4(2):41-62. Leningrad. In Russian.

Vadetskaya EB. 1999. The Tashtyk Epoch in the Ancient History of Siberia. Petersburg's Oriental Studies Print. St. Petersburg. 440 p. In Russian.

Zaitseva GI, Alekseev AYu, Bokovenko NA, Chugunov KV, editors. 2005. Eurasia in the Scythian Epoch: Radiocarbon and Archaeological Chronology. St. Petersburg: Teza. 290 p. In Russian.

Zaitseva GI, Sementsov AA, Lebedeva LM, Pankova SV, Vasiliev SS, Dergachev VA, Jungner H, Sonninen E. 2007. New data on the chronology of the Oglakhty burial-6. Radiocarbon in Archaeological and Paleoenvironmental Research. Proceedings of the 
Conference devoted to the 50th anniversary of the radiocarbon laboratory of the Institute for the History of Material Culture RAS. St. Petersburg: Teza. p 300-7. In Russian.
Zavituhina MP, Barkova LL. 1978. Frozen Tombs: The Culture and Art of the Ancient Tribes of Siberia. London: British Museum. 102 p. 